\title{
Crystallographic Orientation Information by Soft X-Ray Spectroscopy
}

\author{
C.M. MacRae, M.A. Pearce, N.C. Wilson and A. Torpy \\ CSIRO Mineral Resources, Microbeam Laboratory, Clayton South, Australia
}

A field emission electron probe microanalyser (FEG-EPMA) equipped with traditional wavelength and energy dispersive spectrometry, together with soft x-ray emission spectroscopy (SXES) and a cathodoluminescence (CL) spectrometer has been used to investigate a geological sample from a Tanzanian deposit containing graphite, quartz and a number of other minerals. One of the aims of this study was to understand the crystallinity of the graphite, as the geology indicated the ore has been subjected to a heating event up to $800^{\circ} \mathrm{C}$. At these conditions the carbon should be fully crystalline graphite. Initial Raman analysis had shown a mixture of signals indicating the possibility of different crystallinities of graphite. The SXE spectrometer equipped with a Princeton CCD [1, 2] was used to investigate whether different graphite or carbonaceous forms were present while the CL together with trace $\mathrm{Ti}$ analysis, was used to determine the maximum heating temperature using the Tin quartz geothermometry [3]. The sample was mounted in a $25 \mathrm{~mm}$ round, then mechanically polished with a $1 \mu \mathrm{m}$ final lap and to finish the surface, it was ion beam milled at $2 \mathrm{kV}, 5^{\circ}$, for 10 minutes using a Technoorg Linda model SEM Prep2. Prior to examination the sample had a 5nm carbon coat applied. Cathodoluminescence maps were spectrally examined and the $\mathrm{Ti}^{4+} \mathrm{CL}$ peak identified and fitted at each pixel and trace Ti levels measured to calibrate the CL levels as described previously.

For the SXE investigation the mapping was performed at $10 \mathrm{kV}, 70 \mathrm{nA}, 600 \mathrm{~ms}$ dwell with the SXE spectrometer utilising a $200 \mathrm{~N}$ grating that was configured to show from $1^{\text {st }}$ through to $4^{\text {th }}$ order $\mathrm{C} \mathrm{Ka}$ reflections. A spectral examination of the $\mathrm{C} \mathrm{K \alpha}$ line found that the second order reflection offered the best compromise between resolution and signal-to-noise ratio, Fig. 1. C K $\alpha$ spectra from across a number of carbon rich grains clearly showed the graphite structure compared to previous spectra [3, 4]. By selecting several energy regions across the $\mathrm{C} \mathrm{K} \alpha$ peak and projecting these across the mapped area, Fig. 3 , the grains are seen to be composed of graphite with different orientations. Using a scatter plot of the energy regions $260-272 \mathrm{eV}$ vs. $280-284 \mathrm{eV}$ and selecting the end-member clusters the $\mathrm{C} \mathrm{K} \alpha$ spectra are shown in Fig 3. The $\mathrm{C} \mathrm{K} \alpha$ is generated by an electron transition from a $2 p$ orbital to an unfilled $1 \mathrm{~s}$ orbital and theoretical electronic density of states (DOS) calculations by Srbinovsky et al. [5] have shown that the $1 \mathrm{~s}$ DOS contains no structure while the $2 p$ atomic orbitals do have structure therefore the $2 p$ DOS reflect the shape of the $\mathrm{C} \mathrm{K} \alpha$ emission spectra. This study showed that graphite is composed of two distinct spectroscopic forms the $2 p_{(\mathrm{x}, \mathrm{y})}-1 \mathrm{~s}$ and the $2 p_{\mathrm{z}}-1 \mathrm{~s}$ (Fig 4.). The theoretical spectral shapes are good agreement with $\mathrm{C} \mathrm{K} \alpha$ spectra measured using SXE spectrometer [6].

\section{References:}

[1] C.M. MacRae et al, IOP Conf. Series: Materials Science and Engineering 304 (2017), p. 1.

[2] W.P. Leeman et al, Microsc. Microanal. 18 (2012), p. 1322.

[3] J.E. Holliday. Soft X-ray band spectra. Edited by J. Fabian. 1968, pp101-132.

[4] M. Terauchi et al, Handbook of Soft X-ray Emission Spectra, JEOL Ltd, 2016.

[5] J. Srbinovsky et al, Computational and Theoretical Nanoscience 2 (2005), p. 1.

[6] The authors acknowledge the support of the ARC, LE130100087. 


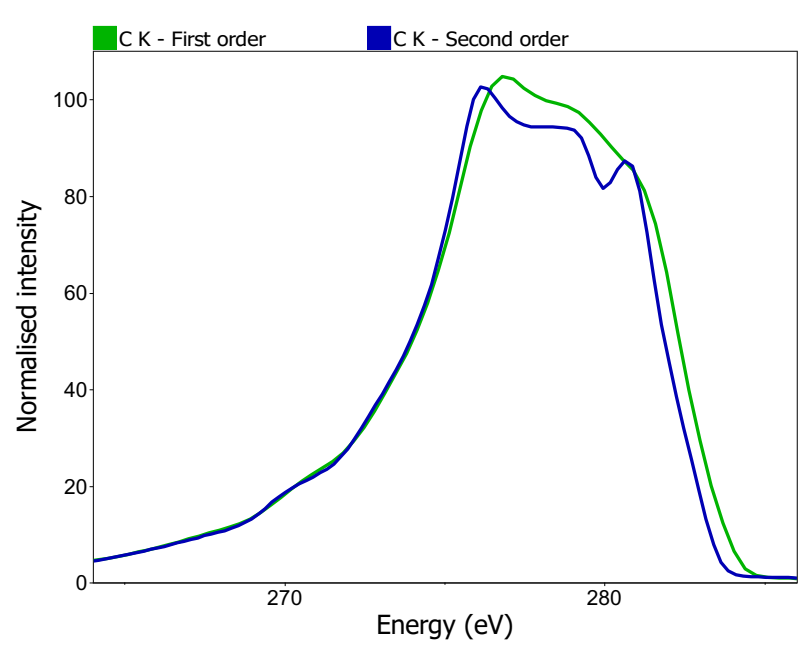

Figure 1. $\mathrm{C} \mathrm{K \alpha} 1^{\text {st }}$ order and $2^{\text {nd }}$ order reflections showing the enhanced resolution of the second order.

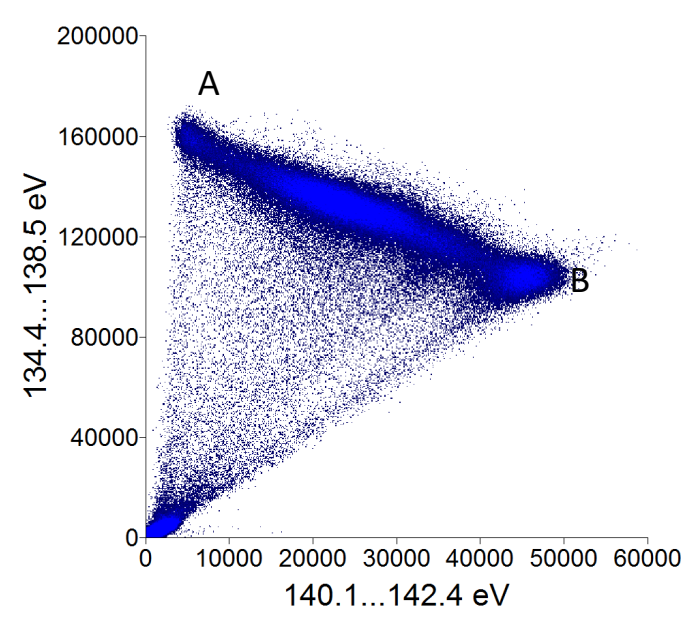

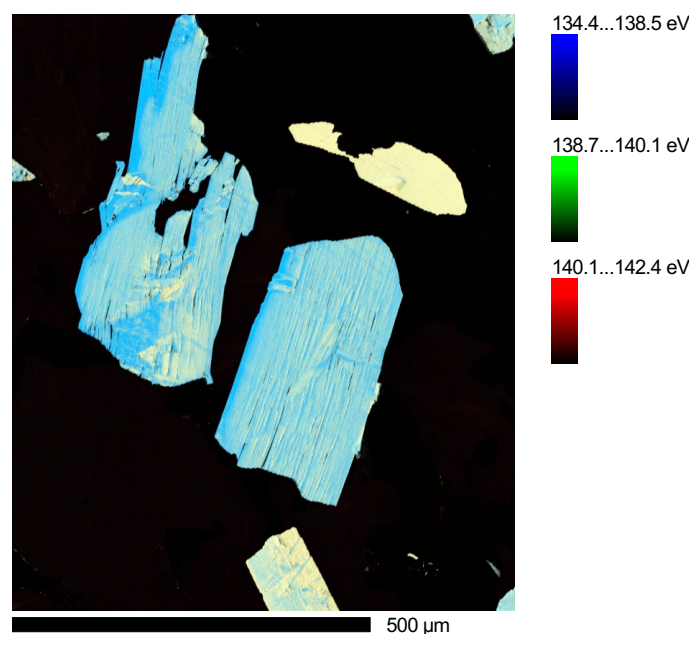

Figure 2. Map showing three ROI across the $2^{\text {nd }}$ order $\mathrm{C} \mathrm{K \alpha}$.

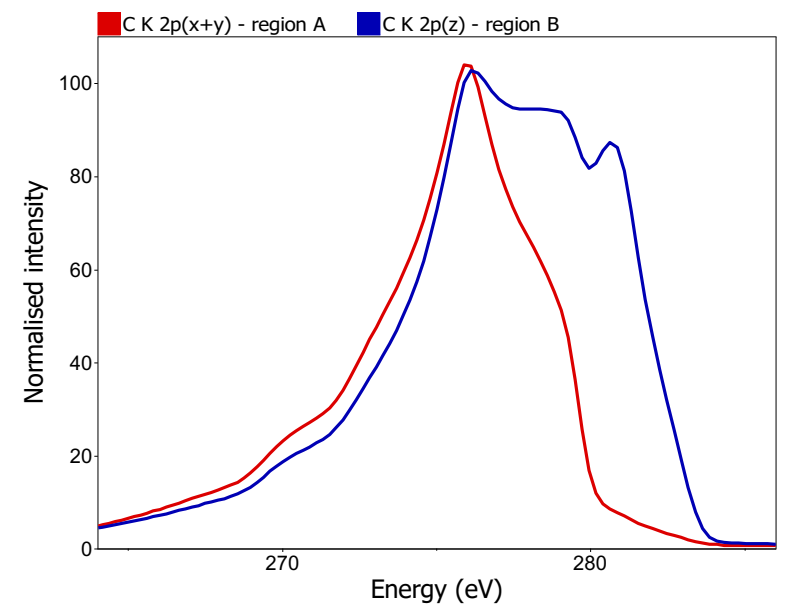

Figure 3. Scatter plot (left) of pixels from two energy regions measured on graphite. Spectra (right) from endmember clusters associated with Region A giving the $\mathrm{C} \mathrm{K \alpha} 2 p(\mathrm{x}+\mathrm{y})$ and Region $\mathrm{B}$ gives the $\mathrm{C} \mathrm{K} \alpha 2 p \mathrm{z}$.

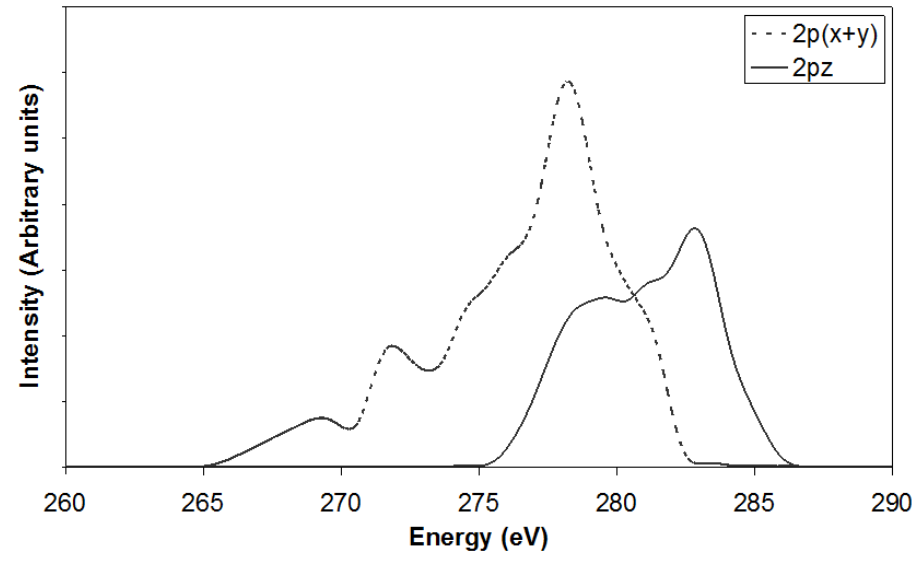

Figure 4. Calculated $\mathrm{C} \mathrm{K} \alpha$ DOS for graphite from Srbinovsky et al. [5]. These match the measured spectra given in Figure 3. 